\title{
AROUSAL EFFECT OF AFFERENT DISCHARGES FROM MUSCLE SPINDLES URON ELECTRO- ENCEPHALOGRAMS IN CATS
}

\author{
Fumiaki MotokIzAwA* AND Bunichi FujImorI \\ Department of Physiology School of Medicine, \\ Hokkaido University, Sapporo, Japan
}

It is well known that EEG arousal response is induced by stimulation of peripheral mixed nerves. As to effects of afferent impulses of muscle nerves upon EEG or upon some neuronal structures in the brain, most of experiments have been carried out by stimulation of muscle nerves (GIAQUINTO, POMPEIANO and Sweet 1963, Mountcastle, Covian and Harrison 1952, Mcintyre 1952, AMASSIAN and BERLIN 1958, OSCARSSON and Rosén 1963). However, judging from the facts that sensory nerve fibers in the muscle nerve are composed of fibers from various receptors such as muscle spindles, tendon organs, Pacinian corpuscles etc., and that each fiber group from these receptors is overlapped in the fiber size, therefore it will be difficult to stimulate selectively a certain group of fibers from specific receptors by means of such a method of stimulation.

In the present experiment, therefore, an attempt has been made to investigate the effect of afferent discharges solely from muscle spindles upon EEG. For this purpose, succinylcholine (Sch) was injected intravenously in cats, on the basis of the previous experimental results that Sch acts directly muscle spindles and produces profuse afferent discharges of group Ia and group II fibers from muscle spindles, at relatively low doses showing appreciable effect neither on the spinal cord nor on other receptors (GRANIT, SkoGlund and Thesleff 1953, Fujimori, Tokizane and Eldred 1959, Henatsch 1962) excepting motornerve terminals (KATO and FuJIMORI 1964).

\section{METHOD}

Experiments were carried out on 25 adult cats weighing from 2.4 to $4.0 \mathrm{~kg}$. Under ether anesthesia, a tracheal cannula was inserted. The animal was mounted in a

Received for publication May 22, 1964

元木沢交昭, 藤森聞一

* Present address: Division of Neurophysiology, Central Clinical Laboratory, Hokkaido University Hospital 
stereotaxic apparatus (Todai Noken type). Procaine was painted to the wound and it was also infiltrated into the orbits and internal auditory meati where the stereotaxic apparatus was attached.

Immediately after cessation of ether inhalation, Flaxedil $(2-4 \mathrm{mg} / \mathrm{kg})$ was injected intravenously and respiration was maintained artificially. Re-administration of Flaxedil. was frequently made at an interval of 60-90 min.

EEGs of the neocortex were picked up from the unilateral anterior sigmoidal, ectosylvian and marginal gyri by means of 3 pairs of enamelled stainless steel wire electrode of $200 \mu$ diameter insulated except at the tip. They were placed $1-2 \mathrm{~mm}$. apart on the dura through holes in the cranium and were fixed to it with dental cement.

EEG of the hippocampus was also picked up with a concentric bipolar electrode inserted into the hippocampus with the aid of the stereotaxic atlas of JASPER and AJMONE MARSAN (1954). The outer tube of the electrode was $0.8 \mathrm{~mm}$ in diameter and the steel wire in it was $200 \mu$ in diameter which was insulated except at the tip. EEGs were recorded by means of an 8 channel electroencephalograph (Model EG-807, San'ei Instrument Co.).

Sch $(0.1 \%, 5-200 \mu \mathrm{g} / \mathrm{kg})$ was injected slowly (in 1-1.5 min.) into the radial or femoral vein 30-50 min. after the above noted administration of Flaxedil when EEGs usually showed a certain stage of sleep pattern.

In some cases, blood pressure was recorded from one femoral artery by means of an electromanometer simultaneously with EEGs.

\section{RESULTS}

1. Effect of Sch upon sleep pattern of EEGs following Flaxedil administration. As reported by HoDEs (1960), EEG synchronization with radom spindle bursts in the neocortex and irregular slow waves in the hippocampus were observed 20-40 min. after Flaxedil administration in 22 cats (FIG. 1) and such sleep patterns of EEGs lasted for 60-90 min. Re-administration of the drug at an interval of 60-90 min. usually produced the same patterns of EEGs.

When Sch injected in dose of $40-200 \mu \mathrm{g} / \mathrm{kg}$ at the above noted stage of EEG patterns in 12 cats, EEGs changed into low voltage, fast activities in the neocortex and into regular slow waves of $3-5 / \mathrm{sec}$ in the hippocampus in 40 $90 \mathrm{sec}$. from the onset of Sch administration in 9 cats (FIG. 2). Such an EEG arousal response lasted for 3-10 min.

Some individual differences in the minimal doses of Sch for the response were observed. That is to say, in a few cats the response appeared in low doses of $10-20 \mu \mathrm{g} / \mathrm{kg}$, whereas most of the cats showed the response in doses over $40 \mu \mathrm{g} / \mathrm{kg}$, although 3 cats did not show any response at a high dose as $200 \mu \mathrm{g} / \mathrm{kg}$.

No appreciable change in blood pressure following Sch administration (50$60 \mu \mathrm{g} / \mathrm{kg}$ ) was observed in association with the EEG arousal response in 3 cats examined (FIG. 3).

It was noticed that the EEG arousal response was similarly obtained with Sch administration $(40-200 \mu \mathrm{g} / \mathrm{kg})$ after the cerebellum was removed in 3 cats. 
A

L. ANT.SIG

9.1.

L.ECT.SYL

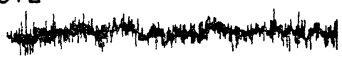

L.MARG

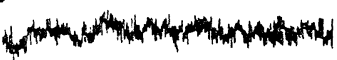

L.HIP

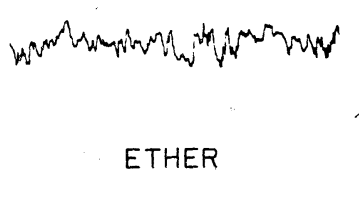

B

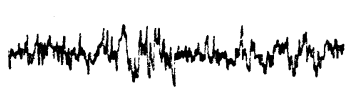

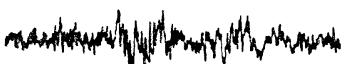

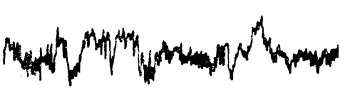

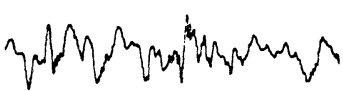

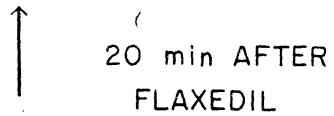

C

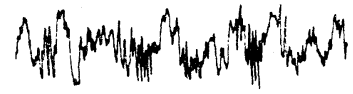

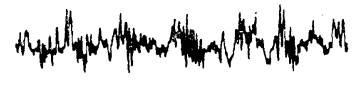

FLAXEDIL i. V.

(4 $\mathrm{mg} / \mathrm{kg}$ )

FIG. 1. Development of sleep patterns of EEGs following

Flaxedil administration.

A : A control record immediately affer cessation of ether inhalation. B : Synchronization in the neocortex and irregular slow waves in the hippocampus develop in $20 \mathrm{~min}$. following Flaxedil (4mg./kg.) administration. C: Sleep patterns of EEGs are completed in $40 \mathrm{~min}$. in the neocortex as well as in the hippocampus.

A $\quad$ B

B

C

D

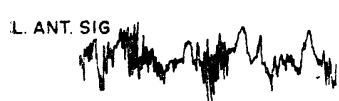

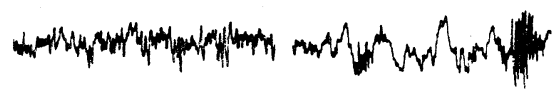

L.ECT. SYL

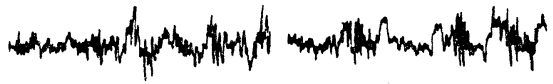

L.MARG

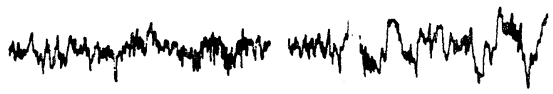

L. HiP

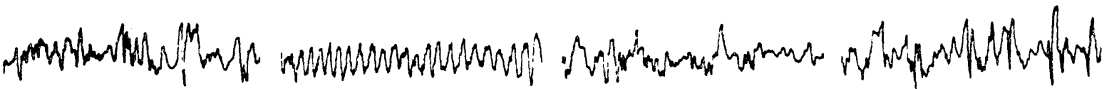

FLAXEDIL

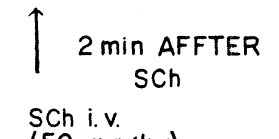

$4 \mathrm{~min}$ AFFTER

$\mathrm{SCh}$

$\int_{1 \mathrm{sec}} 100 \mu \mathrm{v}$

(50 $\mu \mathrm{g} / \mathrm{kg})$

FIG. 2. Arousal effect of Sch upon EEGs.

A : A control record of sleep patterns of EEGs following Flaxedil administration. $\mathrm{B}$ : EEG arousal response in $2 \mathrm{~min}$. following intravenous injection of Sch $(50 \mu \mathrm{g} /$ $\mathrm{kg}$ ), showing desynchronization in the neocortex and synchronization in the hippocampus. C: It gradually recovers in $4 \mathrm{~min}$. D: Recovery is completed in 5 min. 
A

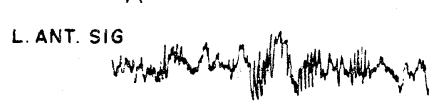

B

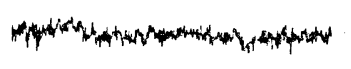

c

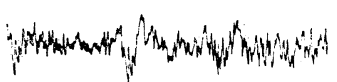
L. HIP

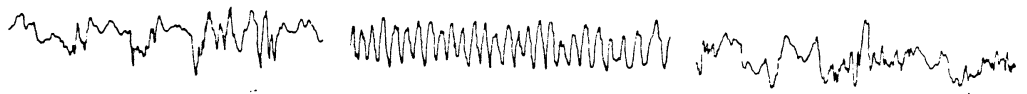
BP

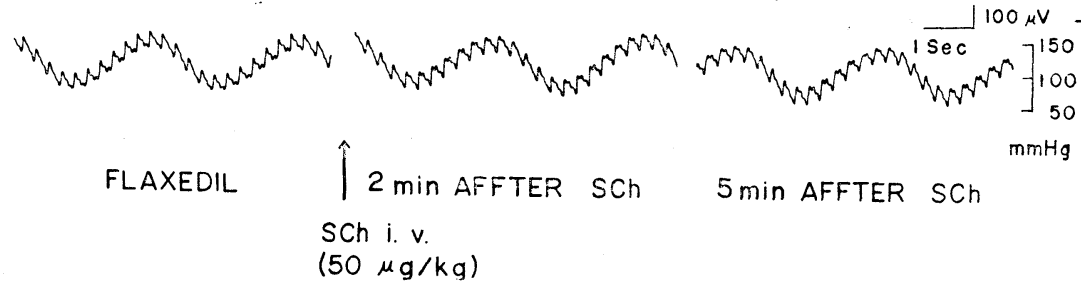

FIG. 3. Effect of Sch upon EEGs and blood pressure.

A : A control record of sleep patterns of EEGs and blood pressure (BP). B : After intravenous injection of $\mathrm{Sch}(50 \mu \mathrm{g} / \mathrm{kg})$, EEG arousal response appears in $2 \mathrm{~min}$. in the neocortex as well as in the hippocampus, whereas no change in blood pressure is recognizable. $\mathrm{C}$ : Arousal response recovers completely in $5 \mathrm{~min}$.

\section{A}

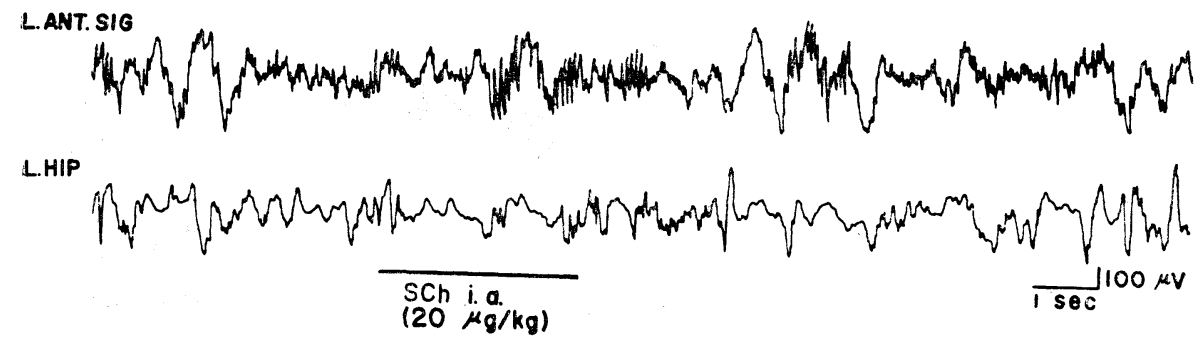

B

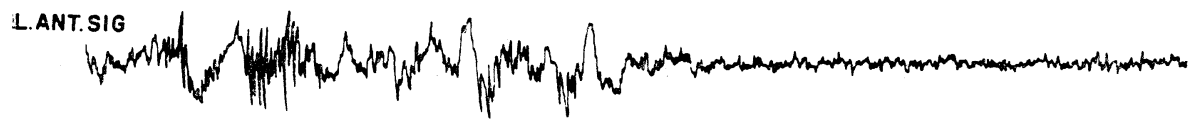

L. HIP

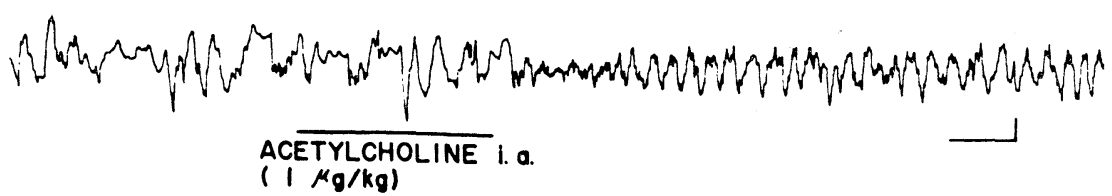

FIG. 4. Effect of intracarotid injection of Sch upon EEGs in comparison with that of acetylcholine.

A : No appreciable change is observed following intracarotid injection of Sch (20 $\mu \mathrm{g} / \mathrm{kg})$. B : Distinct EEG arousal response appears following intracarotid in jection of acetylcholine $1 \mu \mathrm{g} / \mathrm{kg}$ in the same subject $60 \mathrm{~min}$. after $\mathrm{A}$. 
2. Direct effect of Sch upon the brain. In order to investigate whether the above noted arousal effect of Sch upon EEGs is attributable to the afferent discharges from muscle spindles or to the direct effect of Sch upon the brain, two series of experiments were carried out.

In a series of experiments, Sch $(10-40 \mu \mathrm{g} / \mathrm{kg})$ was injected into the internal carotid artery through a cannula inserted into the central cut end of the external carotid artery at the bifurcation in 5 cats.

As a result, no EEG arousal response was recognized in any of the cats. when Sch was administered at the similar stage of sleep patterns of EEGs in the neocortex as well as in the hippocampus following Flaxedil administration. Whereas EEGs were distinctly activated in these cats following intracarotid injection of acetylcholine $(0.2-1.5 \mu \mathrm{g} / \mathrm{kg}$ ) (FIG. 4 ), as reported by RINALDI and HINWICH (1955).

In the second series of experiments, Sch $(40-200 \mu \mathrm{g} / \mathrm{kg})$ was injected intravenously in 4 encéphale isolé preparations under Flaxedil administration in which all the afferent discharges to the brain were eliminated excepting those from the cranial nerves.

As a result, no EEG arousal response was observed in any of them.

\section{A. SCh INJECTION}

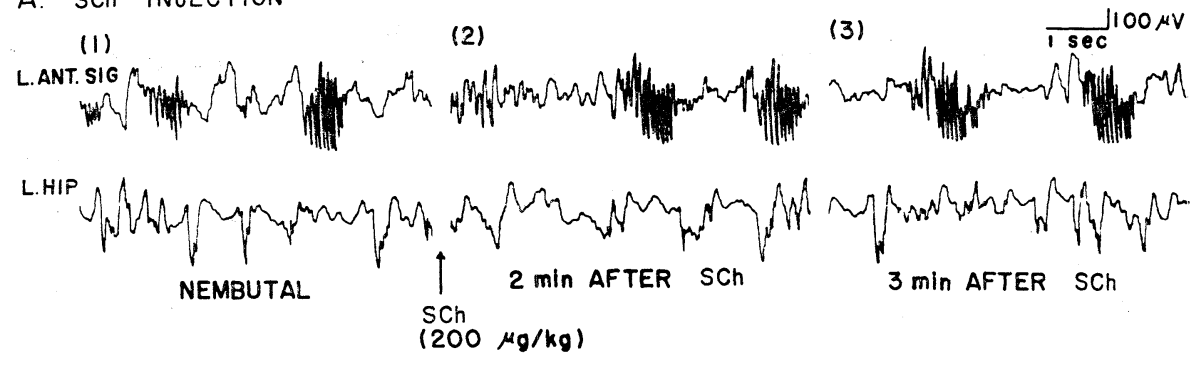

B. sciatic NeRVE stimulation

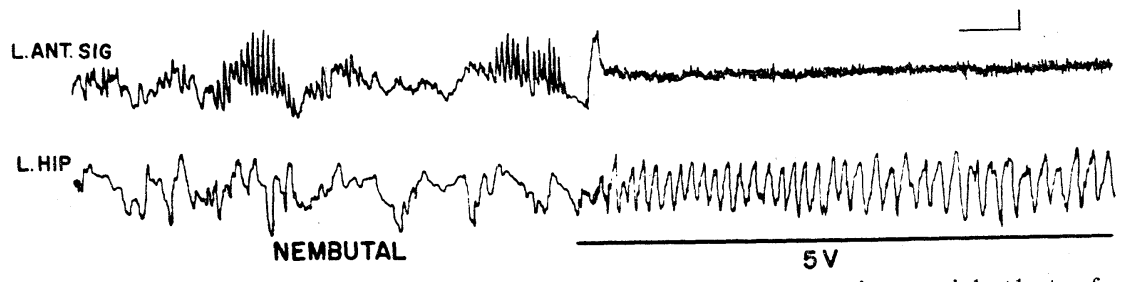

FIG. 5. Effect of Sch administration upon EEGs in comparison with that of sciatic nerve stimulation in a cat anesthetized with Nembutal $(2 \mathrm{mg} / \mathrm{kg})$.

A : No appreciable change in EEGs is observed following Sch $(200 \mu \mathrm{g} / \mathrm{kg})$ administration. B: Distinct arousal response is produced by stimulation of the sciatic nerve in the same subject in the neocortex as well as in the hippocampus (200\% sec. frequency, $0.5 \mathrm{msec}$. duration and $5 \mathrm{~V}$ intensity) $60 \mathrm{~min}$. after $\mathrm{A}$. 
3. Effect of Sch upon sleep patterns of EEGs under Nembutal anesthesia. Sch $(40-200 \mu \mathrm{g} / \mathrm{kg})$ was injected intravenously in 4 cats slightly anesthetized with Nembutal $(2-5 \mathrm{mg} / \mathrm{kg})$ which showed a certain stage of sleep patterns of EEGs, in order to compare the arousal effect of Sch upon EEGs with that of other procedures.

No EEG arousal response was observed by administration of Sch even at high dose of $200 \mu \mathrm{g} / \mathrm{kg}$. Whereas the response was usually obtained in these cats by répetitive stimulation $(200 / \mathrm{sec}$. frequency, $0.5 \mathrm{msec}$. duration and $3-5 \mathrm{~V}$ intensity) of the mesencephalic reticular formation or sciatic nerve as shown in FIG. 5.

\section{DISCUSSION}

GELLHORN (1958) and HODES (1962) suggested that proprioceptive impulses from muscles, tendons, joints and other deep tissues play an important role in maintaining the brain in a vigilant state, on the basis of their experimental results that EEG synchronization was observed following administration of respectively curare and Flaxedil. That is to say, they are of opinion that the synchronization of EEG may be attributable to the reduction of such proprioceptive impulses resultant from relaxation of muscles.

Recently Giaquinto, Pompeiano and Sweet (1963) reported that the EEG arousal response can be induced by group II and group III afferent volleys from muscle nerves, in the case the deep radial or hamstring nerve was stimulated in normal, unrestrained cats.

As to the projection of afferent volleys from muscle nerves to the brain, it has been shown that group I afferent volleys of the muscle nerve in the forelimb reach the cerebral cortex (AMASSIAN and BERLIN 1958, OSCARSSON and Rosén 1963), whereas those of muscle nerves in the hindlimb do not project to the cortex, although those of group II and group III fibers from muscles in the hindlimb as well as in the forelimb do ((Mountcastle, COVIAN and HARrison 1952, McINTYRE 1953). From a different viewpoint, Pompeiano and SweEt (1963) also recognized some difference in the results between those obtained by stimulation of muscle nerves in the upper and lowerlimbs viz., no brain stem unit activity was influenced by stimulation of the hamstring nerve at intensities of stimulation below the threshold for group II fibers, whereas a few units responded to group I volleys of the radial nerve. They attributed this wider effectiveness of the deep radial nerve stimulation to the larger contribution of volleys of afferent fibers from extramuscular receptors in fascias, joints and deep tissues.

1) Mechanisms of the arousal response following Sch administration: In the present experiment, it has been shown that intravenous administration of Sch produced an EEG arousal response in the neocortex as well as in the 
hippocampus in the case of EEG sleep pattern following Flaxedil administration.

As to the mechanism of such an EEG arousal response, the following 3 possible causes may be taken into consideration:

(1) Sch may have a direct action to certain neuronal mechanisms such as the ascending reticular activating system as acetylcholine does (RINALDI and Hinwich 1955).

(2) Possible change in blood pressure may cause the response. As to this problem, BAust, NiEMczyK and VIETH (1963) have suggested that an EEG arousal response induced by intravenous injection of adrenaline is due to the elevation of blood pressure but not a direct action of the drug to the ascending activating system.

(3) Profuse afferent discharges from muscle spindles may reach the brain and produce the response as those of peripheral mixed nerves.

In the present experiment, EEG arousal response was obtained following neither in the case of intracarotid administration of Sch $(10-40 \mu \mathrm{g} / \mathrm{kg})$ in cats immobilized with Flaxedil in contrast with in the case of acetylcholine, nor in the case of intravenous injection of Sch $(40-200 \mu \mathrm{g} / \mathrm{kg})$ in encéphale isolé preparations. Furthermore, CuRTIS, ECCles and ECCles (1957), FujIMORI, TOKIZANE and ELDRED (1959) and FUJIMORI and ELDRED (1961) failed to obtain any evidence of direct action of Sch to the spinal cord, although it has been shown that the drug stimulates also motor nerve terminals and produce antidromic discharges of motornerves in doses above $40 \mu \mathrm{g} / \mathrm{kg}$ (KATO and FUJIMORI, 1964).

On the other hand, it was observed also in the present experiment that there was no appreciable change in blood pressure corresponding to the EEG arousal response induced following Sch administration, as previous reports (FuJIMORI, TOKIZANE and EldRED 1959 SPÖRRI 1962).

Consequently, the above noted two possibilities (1) and (2) may be reasonably excluded from the causes of the arousal response following Sch administration, and the response may be attributable to the afferent discharges of group Ia and group II fibers from muscle spindles.

2) Main courses of the afferent discharges from muscle spindles to the brain: Numerous reports have been published which show that group I volleys from muscle are conveyed to the cerebellum through the spinocerebellar tract (GRundfest and CAMPBell 1942, Lloyd and MCInTyre 1950, CARrea and GrundFest 1954, LAporte, LundBerg and Oscarsson 1956, Oscarsson 1956, Eccles, Hubbard and Oscarsson 1961, Eccles, Oscarsson and Willis, 19ô1, GRANT 1962). On the other hand, it has been demonstrated that cerebellar stimulation can alter the spontaneous activity (WALKER 1938, COOK and SNIDER 1955) as well as the DC potential level of the cerebral cortex (DONOY and SNIDER 1955), 
Therefore, a question arises whether the above noted effect of afferent discharges from muscle spindles upon EEGs may be resultant from the action of the impulses projected to the brain stem or cerebral cortex from the cerebellum.

In the present experiment, however, the EEG arousal response was induced following Sch administration was observed even after completed cerebellectomy. This result is in agreement with that obtained with stimulation of muscle nerves in normal, unrestrained cats (PoMPEIANo and SWEET 1962).

Consequently, it seems unlikely that the EEG arousal response following Sch administration is caused mainly by the secondary action of group I afferents to the ascending reticular activating system via the cerebellum.

3) Intensity of arousal effect of Sch upon EEGs: The arousal effect of afferent discharges from muscle spindles upon EEGs was supposed to be not so strong in comparison with repetitive electrical stimulation either to the ascending reticular activating system or to the sciatic nerve, on the basis of the fact that EEG arousal response under study was solely induced in the case of EEG sleep patterns following Flaxedil administration, but not observed in the case of light Nembutal anaesthesia.

However, it was unable, in the present experiment, to differentiate the effects of discharges of group Ia fibers and group II fibers from muscle spindle.

\section{SUMMARY}

In order to investigate effects of afferent discharges from muscle spindles upon EEGs of the neocortex and hippocampus, succinylcholine (Sch) was administered intravenously in 25 cats immobilized with Flaxedil on the basis of previous reports that Sch affects muscle spindles and produce profuse afferent discharges of group Ia and group II fibers at the doses at which neither its direct effect upon the spinal cord nor upon receptors in the skin was observed. 1. EEG synchronization in the neocortex and irregular slow waves in the hippocampus were usually observed $20-40 \mathrm{~min}$. after Flaxedil $(2-4 \mathrm{mg} / \mathrm{kg})$ administration and it lasted for 60-90 min.

2. When Sch $(40-200 \mu \mathrm{g} / \mathrm{kg})$ was injected intravenously at the above noted light sleep patterns of EEGs generally changed into low voltage, fast activities in the neocortex and into regular slow waves of $3-5 / \mathrm{sec}$. in the hippocampus in $40-90 \mathrm{sec}$. from the onset of Sch administration and these changes lasted for 3-5 min. No appreciable change in blood pressure was observed in association with these EEG arousal response.

Such an EEG arousal response was also obtained even after the cerebellum was removed.

3. The EEG arousal response was recognized neither in the case of intracarotid injection of $\mathrm{Sch}(10-40 \mu \mathrm{g} / \mathrm{kg})$ in cats immobilized with Flaxedil nor 
in the case of intravenous injection of Sch $(40-200 \mu \mathrm{g} / \mathrm{kg})$ in encéphale isolé preparations.

4. On the basis of the above noted experimental results and of direct action of Sch to muscle spindles, the EEG arousal response following Sch administration may be attributable to the afferent discharges from muscle spindles. 5. It was supposed that such arousal effect of Sch was relatively weak in comparison with other procedures usually employed for eliciting EEG arousal response, because the response was not obtained with Sch injection (40$200 \mu \mathrm{g} / \mathrm{kg})$ in cats lightly anesthetized with Nembutal $(2-5 \mathrm{mg} / \mathrm{kg})$ in which distinct responses were observed by stimulation of the mesencephalic reticular formation or sciatic nerve.

This work was supported by research grants from the Rockefeller Foundation and from the Ministry of Education of Japan.

\section{REFERENCES}

1) Amassian, V.E. And Berlin, L.: Early cortical projection of group I afferents in the forelimb muscle nerves of cat. J. Physiol., 143:61, 1958.

2) Baust, W., Niemczyk, H. And Vieth, J.: The action of blood pressure on the ascending reticular activating system with special reference to adrenaline-induced EEG arousal. Electroenceph. clin. Neurophysiol., 15: 63-72, 1963.

3) Carrea, R. M.E. And Grundfest, H.: Electrophysiological studies of cerebellar inflow. I. Origin, conduction and termination of ventral spino-cerebellar tract in monkey and cat. J. Neurophysiol., 17: 208-238, 1954.

4) Cooke, P.M. And Snider, R.S.: Some cerebellar effects on the electroencephalogram. Electroenceph. clin. Neurophysiol., 5: 563-569, 1953.

5) Curtis, D.R., Ecceles, J.C. And Eccles, R. M.: Pharmacological studies on spinal reflexes. J. Physiol., 136: 420-434, 1957.

6) Dondy M. And Snider, R.S.: Slow potential shifts following cerebellar stimulation. Electroenceph. clin. Neurophysiol., $7: 265-272,1955$.

7) Eccles, J.C., Hubbard, J.I. And Oscarsson, O.: Intracellular recording from cells of the ventral spinocerebellar tract. J. Physiol., 158: 486-516, 1961.

8) Eccles, J.C., Oscarsson, O. ANd Willis, W.D.: Synaptic action of group I and II afferent fibres of muscle on the dorsal spinocerebellar tract. J. Physiol., 158: 517-543, 1961.

9) Fujimori, B. And Eldred, E.: Central effects of succinylcholine and decamethonium on monosynaptic reflexes. Amer. J. Physiol., 200: 699-702, 1961.

10) Fujimori, B., Tokizane, T. And Eldred, E.: Effect upon monosynaptic reflexes of decamethonium and succinylcholine. I. Peripheral mechanisms. J. Neurophysiol., 22 : 165-176, 1959.

11) GellHorn, E.: The influence of curare on hypothalamic excitability and the electroencephalogram. Electroenceph. clin. Neurophysiol., 10: 697-703, 1958.

12) Giaquinto, S., Pompeiano, O. And Swett, J.E.: EEG and behavioral effects of fore- and hindlimb muscular afferent volleys in unrestrained cats. Arch. ital. Biol., $101:$ 133-148, 1963.

13) Granit, R., Skoglund, S. and Thesleff, S.: Activation of muscle spindles by succinylcholine and decamethonium. The effects of curare. Acta Physiol. scand., 
$28: 134-151,1953$.

14) Grant, G.: Spinal course and somatotopically localized termination of the spinocerebellar tracts. Acta Physiol. scand., 56 : Suppl. 193, 1-45, 1962.

15) Grundfest, H. And Campbell, B.: Origin, conduction and termination of impulses in the dorsal spino-cerebellar tract of cats. J. Neurophysiol., 5: 276-294, 1942.

16) Henatsch, H. D.: Effects of chemically excited muscle spindles on spinal motoneurones in cats. In: Muscle receptors, edited by BARKER. Hong Kong Univ. Press, Hong Kong, 67-80, 1962.

17) Hodes, R.: Electrocortical synchronization resulting from reduced proprioceptive drive caused by neuromuscular blocking agents. Electroenceph. clin. Neurophysiol., $14: 220-232,1962$.

18) Jasper, H. H. And Ajmone Marsan, C.: A stereotaxic atlas of the diencephalon of the cat. The National Research Council of Canada, 1956.

19) Kato, M. And Fujimori, B.: On the mechanism of fascicular twitching following administration of succinylcholine chloride (1964) (in preparation).

20) Laporte, Y., Lundberg, A. And Oscarsson, O.: Functional organization of the dorsal spino-cerebellar tract in the cat. I. Recording of mass discharges in dissected Flechsing's fasciculus. Acta Physiol. scand., 36: 175-187, 1956.

21) Lloyd, D.P.C. And MCINTyre, A.K.: Dorsal column conduction of group I muscle afferent impulses and their relay through ChARKE's column. J. Neurophysiol., $13:$ 39-54, 1950.

22) McIntyre, A.K.: Cortical projection of afferent impulses in muscle nerve. Proc. Univ. Otago med. Sch., 31: 5-6, 1953.

23) Mountcastle, V.B., Covian, M. R. and Harrison, C. R.: The central representation of some of deep sensibility. Res. Publ. Ass. nerv. ment. Dis., $30: 339-370$, 1952.

24) Oscarsson, O.: Functional organization of the ventral spino-cerebellar tract in the cat. I. Electrophysiological identification of the tract. Acta Physiol. scand., 38 : 145-165, 1956.

25) Oscarsson, O. And Rosen, I.: Cerebral projection of group I afferents in forelimb muscle nerves of cat. Experimentia, 19: 206-207, 1963.

26) Pompeiano, O. And Swett, J.E.: EEG and behavioral manifestations of sleep induced by cutaneus nerve stimulation in normal cats. Arch ital. Biol., 100: 311342, 1962.

27) Pompeiano, O. And Swett, J.E.: Actions of graded cutaneous and muscular afferent volleys on brain stem units in the decerebrates, cerebellectomized cat. Arch ital. Biol., 101 : 552-583, 1963.

28) Rinaldi, F. And Hinwich, H. E.: Alerting responses and actions of atropine and cholinergic drugs. Arch. Neurol. Psychiat., 73: 387-395, 1955.

29) SpÖrRI, H.: U̇ber die Wirkung des Succinylcholines auf den Blutkreisluaf und die Atmung beim Pferd. Helv. Physiol. Acta, 20: 260-272, 1962.

30) WALker, A.E.: An oscillographic study of the cerebellocerebral relationships. J. Neurophysiol., $1:$ 16-23, 1938. 